\title{
Desafios do ensino remoto e sua transição para ensino híbrido na pandemia: a experiência de uma escola
}

Renata Bugança Scheleder", Edilson Pontarolo*

\section{Resumo}

Este trabalho apresenta uma pesquisa descritiva de caráter qualitativo, baseada na análise das experiências de uma escola pública de ensino fundamental durante a pandemia, abordando os desafios do ensino remoto e de sua transição para ensino híbrido. A pesquisa se iniciou questionando os embasamentos legais e a organização das escolas para oferecer essas formas de ensino, problematizando sua implantação e as estratégias utilizadas para o atendimento a crianças de diferentes realidades socioeconômicas. Identificamos as estratégias metodológicas e recursos tecnológicos utilizados pelos professores. A análise dessa experiência reforça a importância do investimento público em recursos tecnológicos e formação continuada dos professores para reduzir os efeitos negativos do distanciamento social, bem como o papel central de políticas públicas que possibilitem uma maior equidade na educação.

Palavras-chaves: Pandemia; Ensino Remoto; Escola Pública.

\section{Introdução}

A situação emergencial atual, ocasionada pela pandemia da Covid-19, fez com que todos os setores da sociedade se reorganizassem, assim foi com a economia, relações sociais, políticas e com a educação formal. Escolas e secretarias educacionais precisaram buscar alternativas para o atendimento aos alunos, pois, diante da

\footnotetext{
Mestra em Desenvolvimento Regional pelo Programa de Pós-Graduação em Desenvolvimento Regional da Universidade Tecnológica Federal do Paraná, Campus Pato Branco. Professora da Rede Pública Municipal de Pato Branco, Paraná. E-mail: renatabuganca@gmail.com

* Doutor em Informática na Educação pela Universidade Federal do Rio Grande do Sul. Professor do Departamento de Informática e do Programa de Pós-Graduação em Desenvolvimento Regional da Universidade Tecnológica Federal do Paraná, Campus Pato Branco. E-mail: epontarolo@utfpr.edu.br
} 
necessidade do isolamento social, a escola precisou alterar a sua prática, deixando de ser presencial e passando ao atendimento remoto.

No município de Pato Branco não foi diferente. Em cumprimento ao Decreto Municipal № 8.659 de 08 de abril de 2020, que suspende desde março de 2020 as aulas presenciais, os 8.046 alunos atendidos na rede municipal, nas modalidades de Educação Infantil e Ensino Fundamental Anos Iniciais, permaneceram fora das escolas. Com o passar dos meses a situação piorou em todo o país, a pandemia tomou proporções ainda maiores e as escolas tiveram que permanecer de "portas fechadas".

Realizada a análise dos primeiros impactos causados pela pandemia no município, a secretaria de educação, junto a secretaria de saúde, passou a organizar-se para iniciar o atendimento aos discentes. Assim, baseado na Deliberação № 01/2020 - CEE/PR, o prefeito assinou o Decreto № 8659 de 08 de abril de 2020, instituindo o regime especial das atividades escolares na forma de aulas não presenciais, iniciando as atividades em 13 de abril de 2020 no formato remoto.

Durante todo o ano de 2020 praticou-se o ensino na modalidade remota. Considerando o Decreto Estadual № 6.637 de 2021, que autoriza a retomadas das aulas presenciais em escolas estaduais, públicas e privadas, e o Decreto Municipal № 8.857, que institui os protocolos de biossegurança a ser observado nas instituições de ensino no município, está sendo realizada a transição do ensino remoto para 0 híbrido, que possui o formato presencial escalonado.

Diante dessas mudanças na educação, este trabalho descreve a experiência de uma escola municipal de Pato Branco nos doze primeiros meses da pandemia da Covid-19, destacando o embasamento legal para o atendimento da modalidade remota e híbrida no Município. Além disso, identificamos como ocorreu a organização das escolas para oferecer esse ensino aos alunos da rede e apresentamos as estratégias utilizadas para o atendimento às crianças de diferentes realidades socioeconômicas da rede municipal, analisando se houve a possibilidade de fornecimento de um ensino igualitário e de qualidade para os alunos.

Considerando que a pandemia tornou mais evidente as dificuldades de muitas escolas em terem acesso aos recursos tecnológicos, assim como a utilização da tecnologia tanto pelos alunos e quanto aos professores. Esse fato se destaca nas pesquisas de Arruda; Silva; Bezerra (2020), Santana; Sales (2020), Souza (2020) e Santos; Santos (2020), concluindo que existem muitos obstáculos a serem superados no meio educacional. 


\section{Metodologia}

Esta pesquisa foi desenvolvida pelas abordagens qualitativa, descritiva com caráter exploratório. Segundo Gil (2008) "Pesquisas exploratórias são desenvolvidas com objetivo de proporcionar visão geral, do tipo aproximativo acerca de determinado fato" (p. 27). Para atingir o objetivo utilizamos a pesquisa documental, através de dados secundários disponíveis nas páginas oficiais da Prefeitura Municipal de Pato Branco, bem como nas publicações no Diário Oficial da União, permitindo o conhecimento amplo e detalhado sobre o objeto de pesquisa (GIL, 2008).

Para apresentar os dados e discutir os resultados, escolhemos o relato de experiência, pois um dos pesquisadores está inserido na realidade estudada como sujeito do estudo realizado, vivenciou e descreve as experiências da equipe escolar de uma escola municipal em que atua. A partir disso, podemos trazer informações detalhadas a respeito da implantação das aulas remotas em tempo de pandemia, especificamente durante o período de março a dezembro de 2020, assim como no processo de transição para ensino híbrido, iniciado em fevereiro de 2021. A escola lócus do estudo está situada na zona urbana, sendo composta por direção, coordenação pedagógica e doze professores. Atualmente a escola oferece Educação Infantil e do primeiro ao quinto ano do Ensino Fundamental - Anos Iniciais, totalizando 120 alunos matriculados.

\section{Resultados e discussão}

$\mathrm{Na}$ escola lócus deste estudo, a maioria dos professores costumam seguir o modelo de aula expositiva, utilizando alguns recursos, dentre eles os mais recorrentes são o livro didático, o projetor multimídia, vídeos e pesquisas sobre os conteúdos abordados na sala de aula. Em muitas situações, mesmo com a utilização de recursos tecnológicos, as práticas costumavam ser centradas no professor. Com a chegada da pandemia o processo de aprendizagem passou a ser um grande desafio, pois descentralizou-se da figura do professor, acelerando a necessidade de nossos alunos compreenderem os conteúdos de maneira autônoma, através de estratégias virtuais disponíveis, desvelando desafios e tensões em relação ao uso das tecnologias na educação pública. 
Com isso, a escola passou a organizar o atendimento remoto, seguindo as orientações do Decreto № 8.659, e em 13 de abril de 2020 iniciaram as atividades

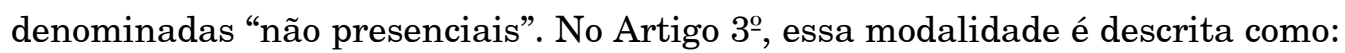

[...] aquelas utilizadas pelo professor da turma destinadas a interação com o estudante por meio de orientações impressas, estudos dirigidos, quinzes, plataformas virtuais, correio eletrônico, redes sociais, chats, fóruns, diário eletrônico, vídeo aulas, áudio chamadas, vídeo chamadas e outras assemelhadas (PATO BRANCO, 2020, p. 01).

O documento também estabelece que sejam organizados os planos de ensino de cada instituição e validados pelo Conselho Escolar da Instituição de Ensino, segundo orientações da Deliberação 01/2020- CEE/PR e 09/2020, além de descrever as atribuições dos professores, coordenadores e Secretaria Municipal de Educação - SMEC.

O Ensino remoto iniciou na escola com a organização dos Componentes Curriculares dos bimestres presentes na Proposta Pedagógica Curricular Municipal, Base Nacional Comum Curricular, Referencial Curricular do Estado do Paraná, Projeto Político Pedagógico e elaboração do plano de ação que foi encaminhado ao Conselho Escolar, sendo aprovado ao final da avaliação.

Muitas angústias se fizeram presentes nesse período, sobre como conseguiríamos desenvolver as aulas de modo que os alunos tivessem acesso e proximidade com os professores, que acreditam que o ensino e a afetividade da interação presencial face-a-face desempenham papel essencial para a aprendizagem. Diante disso, foi decidido, por unanimidade, que a utilização do aplicativo WhatsApp cumpriria o papel de comunicação entre as famílias e a escola, sendo criados grupos por turmas, inseridos pais ou responsáveis, professores, coordenação e direção. Também foi criado um grupo de WhatsApp exclusivo dos professores, possibilitando o compartilhamento de estratégias de ensino, trocas de experiência e outras informações.

Os professores realizavam o planejamento das atividades junto com a coordenadora e, semanalmente, disponibilizavam os materiais, por meio de pastas no Google Drive. Nesse ambiente virtual a Secretaria de Educação acompanhava o planejamento, podendo visualizar os planos de ensino, vídeos entre outras sugestões de atividades. $\mathrm{O}$ acesso dos alunos e responsáveis ocorreu por meio do portal do município http://wwwpatobranco. gov.br/, através da funcionalidade "Atividades em Casa" (Figura 1) agregada para essa finalidade, ou diretamente por meio do endereço http://www.atividadesemcasa.com.br/. Ao entrar, os alunos e familiares deveriam selecionar a escola e, na sequência, a turma matriculada. 
Figura 1: Portal "Atividades em casa" criado pela SMEC de Pato Branco

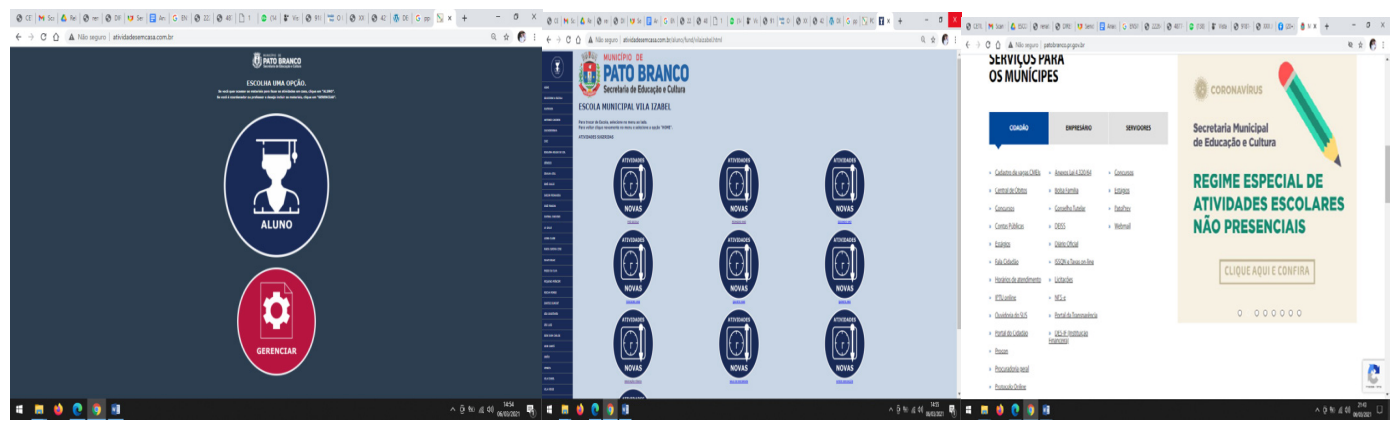

Fonte: Reproduzido de http://www.atividadesemcasa.com.br/

Os professores também encaminhavam atividades pelos grupos de WhatsApp e enviavam orientações aos pais por meio de áudios, vídeos, mensagens e vídeo chamadas.

Aos alunos socialmente mais vulneráveis, a direção da escola realizou a entrega dos materiais de forma impressa, através de escalas a fim de evitar aglomerações na hora da retirada, e em muitas vezes, mediante as dificuldades encontradas pelas famílias, a diretora precisou entregar as atividades diretamente na casa de alguns alunos. A equipe pedagógica manteve a escola aberta, realizando atendimentos às famílias e suporte aos professores em consonância com os protocolos de segurança sanitária.

Para a realização das atividades de forma virtual assíncrona, a metodologia foi pautada no uso de tecnologias que possibilitassem a mediação pelo professor, levando em consideração que os alunos possuem de quatro a dez anos de idade, além de que realizam as atividades, na maior parte, com o acompanhamento de seus familiares, no período da noite e em finais de semana.

Diante do cenário pandêmico, a devolutiva das atividades ocorreu através de fotos e vídeos enviados pelo WhatsApp, e que também poderiam ser entregues na escola, seguindo um cronograma organizado pela direção e coordenação. Os professores arquivaram as atividades, com pastas para cada aluno, contendo ali o acompanhamento individual descritivo e, quando necessário, passado à coordenação a necessidade de conversar com os responsáveis, a fim de auxiliá-los no que fosse necessário. Outra forma de registro foi o Livro de Registro On-line (LRCOM), seguindo a orientação № 04/2020 SEED/DPGE/DLE/CDE e a Orientação Conjunta n. 009/2020 DEDUC/DPGE/SEED. Dessa forma, o ano letivo de 2020 foi concluído 
no dia 19 de dezembro de 2020, validado pelo Conselho Escolar, atendendo aos dispositivos da Lei de Diretrizes e Bases da Educação Nacional LDBE № 9.394/96, a Deliberação № 09/2020- CP/CEE/PR e a Resolução № 5.003/2020 - GS/SEED tendo a provação da Secretaria de Educação através da Declaração emitida pela secretária em exercício na data de 22 de dezembro de 2020.

No ano de 2021 o ano letivo iniciou na modalidade remota, utilizando-se das mesmas estratégias adotadas no ano de 2020. Os professores retornaram à escola para organização do ano letivo e planejamento, seguindo todos os protocolos de segurança orientados pela Secretaria de Saúde do Estado e do Município.

Além disso, a Secretaria de Educação buscou implementar outras ferramentas de ensino. Desse modo, foi encaminhado às escolas para adesão do Google Clasroom, alguns professores optaram por utilizá-lo e iniciaram o processo de organização dos e-mails institucionais e cadastros, a fim de disponibilizar o acesso às turmas de quarto e quinto anos da rede municipal. Para o melhor aproveitamento, será fornecida uma capacitação aos professores e espera-se que com seu uso, possa ter mais interação entre alunos e professores. Ademais, os professores também terão acesso a tutoriais sobre o funcionamento do Google Meet, ferramenta para a aula on-line síncrona, que permite gravar a aula e, posteriormente, liberá-la aos alunos que não conseguiram acessar em tempo real. Em muitas situações, a escola tem se organizado para auxiliar os professores com maior dificuldade, bem como enviando aos pais tutoriais de acesso e participação.

Em cumprimento ao Decreto Estadual № 6.637, que autoriza a retomadas das aulas presenciais em escolas estaduais, públicas e privadas, o município iniciou a organização e a transição para modalidade de ensino híbrido, sendo presencial escalonada. Em consonância com o Decreto № 8.857, que institui os protocolos de biossegurança, as instituições de ensino no município devem organizar seus espaços físicos e aguardar a aprovação dos órgãos responsáveis pela avaliação.

Entretanto, até o início de março de 2021, nenhuma escola da rede municipal forneceu aos alunos o ensino no formato híbrido. A única medida executada foi a publicação, pela SMEC, da Portaria № 001/2021, que descreve como se dará os atendimentos, respeitando a medida de distanciamento na escola, de modo que os alunos permanecerão uma semana na escola e uma semana com atividades remotas em casa com material impresso. Os pais e responsáveis podem escolher a modalidade híbrida, ou apenas pelo ensino remoto. Segundo o planejamento do município, as 
aulas não serão de forma síncrona, pois não há equipamentos adequados para a realização e não se tem previsão de investimentos nessa área.

Em relação a participação dos alunos no ensino remoto, que tinha como objetivo promover a todos o acesso a escola e aos conteúdos sistematizados, por meio dos recursos tecnológicos ou materiais impressos, evitou uma possível evasão escolar. Foi realizado um trabalho minucioso através das planilhas de acompanhamento individual dos alunos, e ao perceber que o aluno não estava realizando as atividades, a coordenadora entrava em contato com os responsáveis do discente, para que de alguma forma, pudessem possibilitar o acesso. Diante de determinadas realidades, alguns alunos foram atendidos de forma presencial na escola, com todos os protocolos de segurança e em horários agendados, ocorrendo de forma individual um auxílio às crianças.

Sobre as dificuldades encontradas na implantação e atendimento dos educandos e familiares nessa modalidade, observamos a falta de conectividade de algumas famílias. Situação decorrente do fato de que, muitas vezes, possuem apenas um celular que é utilizado pelos pais, assim as crianças têm acesso somente nos finais de semana ou realizam apenas as atividades impressas, o que dificulta a compreensão dos conteúdos.

Uma das preocupações sobre o ensino e aprendizado é em relação a impossibilidade de realizar discussões dos conteúdos, contextualização e a ausência de interação com os alunos, pois somos seres sociais e a escola possui sua prática fundamentada na teoria Pedagogia Histórico-Crítica, a qual compreende-se que, a educação e a escola, da forma que hoje conhecemos, é resultado de um processo de transferência histórica, nos contextos culturais, sociais e econômicos. Para Saviani (2014) é "ato de produzir diretamente e intencionalmente, em cada indivíduo singular, a humanidade que é produzida historicamente e coletivamente pelo conjunto de homens” (SAVIANI, 2014, p. 25).

Dessa forma, se faz necessário um planejamento das ações, para que o aluno possa, com êxito, ter acesso ao saber sistematizado, levando em consideração a sua construção social, o que é comprometido quando as atividades são apenas impressas.

Outra dificuldade foi em relação aos professores, muitos não utilizavam ferramentas tecnológicas para fins pedagógicos, como computadores, celulares, muitos não tinham conhecimento de aplicativos que pudessem auxiliar nas gravações e programas de edição de vídeos, alguns não dispunham de equipamentos adequados, enquanto outros demonstraram resistência em inserir-se esses recursos em seus planejamentos. A escola também possui poucos equipamentos tecnológicos, alguns já ultrapassados, situação que dificultava o trabalho dos professores. 
O ensino remoto expôs uma deficiência do sistema público educacional, a inclusão digital de professores e alunos. Segundo Cunha (2020), diretor executivo do grupo Positivo,

Enquanto alunos de escolas particulares aprendem por meio de diversos recursos e estratégias combinadas, como vídeo ao vivo ou gravado, envio de tarefas, mentoria e sessões em grupos menores para tirar dúvidas, muitos estudantes das escolas públicas sequer têm acesso à internet (CUNHA, 2020, p. 1).

Essa realidade ficou comprovada na escola objeto deste estudo, pelo fato de que a maioria dos alunos retirou, na instituição de ensino, as atividades impressas alegando dificuldade de acesso à internet e impressão do material.

A educação é um direito de todos garantido pela Constituição Federal (1988) em seu Artigo 205, porém neste tempo de pandemia ficou ainda mais evidente que o acesso não tem sido igualitário, distanciando ainda mais as classes sociais do Brasil e o acesso ao conhecimento sistematizado. Saviani (2014) declara que

[...] a escola tem a ver com o conhecimento científico e não com o conhecimento cotidiano, o povo precisa da escola para tem acesso às formas elaboradas, inclusive para expressar de modo elaborado a sua cultura, os seus interesses, a sua visão de mundo (SAVIANI, 2014, p. 29).

O distanciamento necessário dificulta o trabalho pedagógico que possui sua base na prática social. De forma urgente precisamos ter políticas públicas eficientes que diminuam esse abismo de acesso ao conhecimento possibilitando que os alunos do sistema público tenham garantido seus direitos educacionais.

Pretto; Bonilla; Sena (2020) destacam que os docentes, em regra geral, acessam e se apropriam com facilidade das redes sociais digitais, mas não conseguem articular esse uso com o cotidiano escolar, pois são lógicas diferentes que não dialogam. $\mathrm{Da}$ mesma forma, os alunos acessam alguns locais na rede como Youtube, WhatsApp, jogos e vídeos para entretenimento, porém quando relacionado as temáticas educacionais, sentem a necessidade de auxílio e acompanhamento. Não podemos deixar de mencionar que, em muitas situações está sendo atribuído aos professores a responsabilidade em assumir os custos relacionados a infraestrutura física e tecnológica, o que em muitas situações acaba ficando de forma inacessível, pois não tiveram amparo da mantenedora em relação aquisição de novos equipamentos e cursos específicos.

A escola possui um papel fundamental para o desenvolvimento dos alunos, não se caracteriza apenas como um local de busca de conhecimento sistematizado, 
mas constitui um lugar de convivência, aprendizado e diversidade, que possibilita relações sociais e precisa ser olhada com zelo e respeito.

Vale pontuar que, com a adoção de novas tecnologias, o ensino nas modalidades remota e híbrida reduzem um pouco a sensação de distanciamento entre os alunos e a escola, proporcionando atividades dinâmicas e estimulando a curiosidade. Os recursos tecnológicos atraem a atenção dos alunos, incentivando a sua autonomia e a busca pelo conhecimento. À medida que os professores foram adquirindo a consciência do seu papel e sua importância, procuraram formações e novas possibilidades de desenvolverem suas funções, levando-os a experimentarem novas formas de aprender e de ensinar.

Desse modo, também se faz necessário um olhar para a formação dos professores e a possibilidade de todos terem acesso aos equipamentos, pois nesse tempo de isolamento, a educação precisa da tecnologia. Além disso, precisamos de um envolvimento dos responsáveis pelos alunos, no acompanhamento e organização na realização das atividades. Diante dessa realidade, é essencial repensar a relação família e escola, com um olhar de empatia, sem julgamentos, pois esse é um momento delicado que afeta a todos os indivíduos da sociedade.

\section{Considerações Finais}

Ao finalizar este relato de experiência, vivenciado em uma escola pública municipal no período dos doze primeiros meses de pandemia da Covid-19, observamos a importância da busca por recursos tecnológicos, a fim de reduzir os efeitos negativos do distanciamento social. Entretanto, os desafios que já eram imensos no cenário da educação básica do Brasil, ganharam proporções ainda maiores com a falta de investimentos em formação dos professores e equipamentos nos espaços escolares públicos, assim como a necessidade de políticas públicas educacionais a fim de promover uma equidade no ensino.

Os professores da rede municipal, acostumados com o modelo presencial, precisaram se reinventar, pois em sua maioria não se sentiam capacitados ou preparados. Diferentemente do ensino à distância, modalidade com equipamentos e equipe multiprofissional que pensa na transmissão, gravação e edição, os professores municipais estão de forma "caseira" dando o seu melhor, em busca de atender seus alunos. Essa situação é coerente com as ideias defendidas por Feenberg (2013, p. 172). 
Nenhum profissional de computador precisa ser envolvido; como na sala de aula convencional, muito do interesse se encontrará na interação entre os próprios estudantes e entre estes e os professores. Da mesma forma, com as técnicas de aulas, para elas deve-se esperar um amadorismo saudável.

O Ensino híbrido, previsto para iniciar no ano letivo de 2021 ainda não foi implementado por motivo do aumento significativo de contaminados e óbitos por Covid-19 no município. As escolas estão autorizadas para o retorno no formato escalonado com previsão de início em 20 de março de 2021.

No ano de 2021, para dar continuidade às atividades, sejam remotas, híbridas ou presenciais, faz-se necessário um diálogo maior entre os gestores, professores e comunidade escolar, para construir uma escola mais acolhedora e democrática.

Com a expectativa do retorno das aulas em modelo híbrido, consideramos fundamental a continuação e ampliação do uso dessas tecnologias, e esperamos que logo possamos receber os alunos de forma segura nos espaços escolares.

\section{Challenges of remote education and its transition to hybrid teaching in pandemic: the experience of a school}

\section{Abstract}

This work presents a qualitative descriptive research, based on the analysis of the experiences of a public elementary school during the pandemic, addressing the challenges of remote education and its transition to hybrid education. The research started by questioning the legal bases and the organization of schools to offer these forms of teaching, questioning their implementation and the strategies used to assist children from different socioeconomic contexts. We identified the methodological strategies and technological resources used by teachers. The analysis of this experience reinforces the importance of public investment in technology and continuing education for teachers, to reduce the negative effects of social distance, as well as the central role of public policies that enable greater equity in education.

Keywords: Pandemic; Remote Learning; Public School.

\section{Referências}

ARRUDA, Graziela Queiroz de; SILVA, Joelma Santana Reis da; BEZERRA, Maria Aparecida Dantas. O uso da tecnologia e as dificuldades enfrentadas por educadores e educandos em meio a pandemia. In: CONEDU VII Congresso nacional de educação. 2020, Maceió. Anais eletrônico... Editora Realize, 2020. Disponível em: https://editorarealize.com.br/editora/anais/conedu/2020/ TRABALHO_EV140_MD1_SA_ID2426_04092020084651.pdf. Acesso em: 7 mar. 2021. 
ATIVIDADES EM CASA. Disponível em: http://www.atividadesemcasa.com.br/. Acesso em: mar. 2021.

BRASIL. Constituição. Constituição da República Federativa do Brasil. Brasília, DF: Senado Federal: Centro Gráfico, 1988.

CUNHA, Paulo Arns da. A pandemia e os impactos irreversíveis na educação. Revista Educação. 15 abr. 2020. Disponível em: https://revistaeducacao.com.br/2020/04/15/pandemia-educacao-impactos/. Acesso em: 8 mar. 2021.

FEENBERG, Andrew. A fábrica ou a cidade: qual o modelo de educação a distância via web? In: NEDER, R. T. A teoria crítica de Andrew Feenberg: racionalização democrática, poder e tecnologia. Brasília: Observatório do Movimento pela Tecnologia Social na América Latina / CDS / UnB / Capes, 2013.

GIL, Antonio Carlos. Métodos e técnicas de pesquisa social. 6 ed. São Paulo: Atlas, 2008.

PATO BRANCO. Decreto Municipal no 8659 de 08 de abril de 2020. Disponível em: http:// www.município.pr.gov.br/wp-content/uploads/2020/05/DECRETO-\%C2\%BA-8.659-DE-8-DE-ABRIL-DE-2020.pdf. Acesso em: 8 mar. 2021.

PATO BRANCO. Decreto Municipal n. 8.857 de 18 de fevereiro de 2021. Disponível em: http://município.pr.gov.br/wp-content/uploads/2021/02/Decreto-Protocolo-Biosseguranca-Educacao. pdf. Acesso em: 10 mar. 2021.

PATO BRANCO. Decreto Estadual n 6.637 de 20 de janeiro de 2021. Disponível em: https:// www.legisweb.com.br/legislacao/?id=408347. Acesso em: 9 mar. 2021.

PRETTO, Nelson de Luca; BONILLA, Maria Helena Silveira; SENA, Ivânia Paula Freiras de Souza. Educação em tempos de pandemia: reflexões sobre as implicações do isolamento físico imposto pela COVID-19. Salvador: Edição do autor, 2020. Disponível em: https://blog.ufba.br/gec/ files/2020/05/GEC_livro_final_imprensa.pdf. Acesso em: 10 mar. 2021.

SANTANA, Camila Lima Santana e; Sales, Kathia Marise Borges. Aula em casa: educação, tecnologias digitais e pandemia Covid-19. Interfaces Científicas. n. 10, v. 1, 2020, p. 75-92. Disponível em: https://periodicos.set.edu.br/educacao/article/view/9181. Acesso em: 8 mar. 2021.

SANTOS, Nádson Araújo dos; SANTOS, Roseane Araújo dos. Tecnologias digitais e ensino remoto: reflexões outras sobre as precariedades diante da pandemia. Revista da Abralin, v. 19, n. 2, p. 1-5, 2020. Disponível em: https://revista.abralin.org/index.php/abralin/article/view/1568/1563. Acesso em: 10 mar. 2021.

SAVIANI, Dermeval. A pedagogia histórico-crítica. Revista Binacional Brasil Argentina. Vitória da Conquista, v. 3, n. 2, p. 11-36, dez. 2014. Disponível em: https://periodicos2.uesb.br/ index.php/rbba/article/view/1405/1214. Acesso em: 9 mar. 2021.

SOUZA, Elmara Pereira de. Educação em tempos de pandemia: desafios e possibilidades. Caderno de Ciências Sociais Aplicadas. v. 17, n. 30, jul./ dez. 2020. p. 110-118. Disponível em: https:// periodicos2.uesb.br/index.php/ccsa/article/view/7127/5030. Acesso em: 9 mar. 2021. 